\title{
Social and Environmental Challenges
}

Climate change, loss of (bio)diversity, natural resource depletion, social marginalization etc.: Our adaptation and mitigation contribution.

Fish bowl discussion, Mon, 13 Oct 2014, 16:30 - 18:00

\section{Background}

The environmental and social challenges of the planet are a sad reality. Organic Agriculture advocates often espouse its contributions to mitigating the negative effects of farming. But mitigation alone is not enough. Farmers also need to adapt to a changed climate, reduced biodiversity and depleted resources as well as to an ever-changing socio-cultural environment.

\section{Session Objectives}

This session will look into the mitigation contributions and the potentials to measure, communicate and improve the impact of organic farming. It will also explore the coping strategies of organic farmers around the globe, in order to improve their livelihoods not only economically but also environmentally, socially and culturally.

\section{Questions:}

1. What are the main environmental and social challenges relevant for Organic Agriculture?

AG: Agriculture and food production in general has to cope with on-going land and soil degradation, at the one side and with an increasing demand for food and energy on the other side, both in the context of a changing climate. These are important challenges for agriculture in general and organic agriculture in particular. Concepts and solutions are urgently needed in regions with a high competition for biomass. There are trade-offs for biomass usage like human and animal consumption/fuel and raw material/ and soil organic matter reproduction and soil management. The Focus Group on Organic Farming of the European Innovation Partnership for Agricultural Productivity and Sustainability (EIP-AGRI) has identified five main causes of the yield gap be-tween organic and conventional arable cropping: i) inadequate nutrient supply, ii) poor soil fertili-ty management, iii) insufficient weed management, iv) pest and disease pressure insufficiently managed and $v$ ) not systemconform crop varieties (report not yet published).

\section{How does Organic Agriculture contribute to the mitigation of these challenges and how can we measure and communicate its impacts?}

AG: Agriculture can contribute to the mitigation of these challenges by a systematic implementation of sustainable management practices in food production systems as organic agriculture (OA) aims at. This can be reached by applying the concept of eco-functional 
intensification which starts with the embedding of ag. systems into the site-specific biophysical and socio-economical context and closing nutrient cycles which takes also the human waste and household refuse into consideration. OA provides already quite a bunch of concepts aiming at a closing nutrient cycles at farm and community level.

\section{Are we on the right track or do we need strategy changes?}

AG: $O A$ is definitely on the right track, by implementing a systems approach rather than building upon single practices. However, solutions are required to enable food production and sufficient crop growth under harsh conditions such as on degraded soils. The combined application of organic and synthetic fertiliser for a certain time to enhance crop growth and stimulate soil formation at the same time might be worth to think about.

\section{Do we have conflicts of interests? What about conflicts of priorities?}

AG: We do certainly have conflicts of interests if synthetic fertilisers are allowed to some extent and this certainly leads to a conflict of priorities: Do we want to develop soils as the living basis first and then feed people or should we rather go for a compromise like feeding people and developing soils right from the beginning by following an approach that allows for an integrated plant production concept at least for the first 5-10 years.

\section{What would help Organic farmers to better adapt to existing environmental challenges?}

AG: Farmers should be aware that production conditions may change rapidly especially in environments of weather extremes. A further development towards higher farm diversification where failures of production activities can be compensated by another might be one strategy to strengthen the adaptive capacity of organic farmers. These concepts should rather build upon the implementation of on-farm resources (= eco-functional intensification) rather than applying external organic inputs which create new dependencies and restrictions.

\section{How should we cope with socio-cultural challenges?}

AG: What is meant by that? Examples? 